\title{
Use of eco-benign periwinkle shell particle for making composites and study their effect on the thermal and mechanical properties of novel HDPE composites
}

\author{
Abbas Saifee Valsadwala \\ University of Akron
}

\section{Sriram Srinivasan}

Rochester Institute of Technology

\section{Surya Rajan Balachandran}

B S Abdur Rahman Crescent Institute of Science \& Technology

Shamshath Begum ( $\square$ sshamshath@crescent.education )

B S Abdur Rahman Crescent Institute of Science \& Technology https://orcid.org/0000-0002-2253-536X

Asit Baran Samui

Institute of Chemical Technology

Sandeep Kumar Shukla

Mahindra and Mahindra Ltd

\section{Research Article}

Keywords: Periwinkle shell powder, HDPE, composites, eco-benign filler, extension evaluation method

Posted Date: November 22nd, 2021

DOI: https://doi.org/10.21203/rs.3.rs-1072237/v1

License: (c) (i) This work is licensed under a Creative Commons Attribution 4.0 International License.

Read Full License 


\section{Use of eco-benign periwinkle shell particle for making composites and study their effect on the thermal and mechanical properties of novel HDPE composites}

Abbas Saifee Valsadwala ${ }^{a}$, Sriram Srinivasan ${ }^{b}$, Surya Rajan Balachandran ${ }^{c}$, S Shamshath Begum ${ }^{c *}$ Asit Baran Samuid and Sandeep Kumar Shukla ${ }^{\mathrm{e}}$

a Department of Polymer Engineering, University of Akron, Akron, Ohio, USA

${ }^{b}$ Department of Packaging Science, College of Engineering Technology, Rochester Institute of Technology

'Department of Polymer Engineering, B. S. Abdur Rahman Crescent Institute of Science and Technology, Chennai, Tamil Nadu, India

dInstitute of Chemical Technology, N.C.Parekh Marg, Mumbai, 400019, India

eMahindra \& Mahindra, Mahindra Research Valley, Tamil Nadu, India

${ }^{*}$ Corresponding author : Dr. S. Shamshath Begum, Assistant Professor (Sr.Gr.), Department of Polymer Engineering, B. S. Abdur Rahman Crescent Institute of Science and Technology, Chennai, Tamil Nadu, India.

Email: sshamshath@crescent.education

\section{ABSTRACT}

In this investigation, the shell powder of Littorina littorea commonly called periwinkle was used as an eco-benign filler in High-Density Polyethylene (HDPE) to form periwinkle/HDPE composites (PHPC). Understanding the effect of different particle sizes of periwinkle shell powder (PSP) and optimizing their influence on PHPC is the main scope of work. Periwinkle shell (PS) particle sizes from $<53 \mu \mathrm{m}$ to $150 \mu \mathrm{m}$ were chosen as reinforcement. The different PSP size like $<53 \mu \mathrm{m}, 53 \mu \mathrm{m}, 75 \mu \mathrm{m}, 90 \mu \mathrm{m}$, $105 \mu \mathrm{m}$ and $150 \mu \mathrm{m}$ chosen in this study were named as PHPC ${ }_{53}, \mathrm{PHPC}_{53}, \mathrm{PHPC}_{75}$, $\mathrm{PHPC}_{90}, \mathrm{PHPC}_{105}$, and $\mathrm{PHPC}_{150}$ respectively. The composites were fabricated by incorporating 1 weight \% of PSP into HDPE matrix using compression molding technique and then subjected to morphological, thermal, and mechanical characterizations. Morphology studies using scanning electron microscope (SEM) confirms $150 \mu \mathrm{m}$ PSP had best dispersion whereas $75 \mu \mathrm{m}$ PSP resulted with agglomeration. PSP had little influence on the thermal stability of HDPE except for $\mathrm{PHPC}_{150}$ which showed rise in degradation temperature when compared to the neat sample. Mechanical properties such as hardness, Young's modulus, impact strength, and flexural modulus were enhanced by the addition of PSP. Whereas, a decrease was noted in elongation at break (\%) and flexural strength of PHPC indicating the stiffening effect of filler on HDPE. In order to understand the particle size influence better, the extension evaluation method (EEM) was performed for all samples and PHPC $_{150}$ was found to be the best performing among all particle sizes.

KEYWORDS : Periwinkle shell powder; HDPE; composites; eco-benign filler; extension evaluation method 


\section{INTRODUCTION}

Polymer matrix composites (PMCs) have become ubiquitous across the globe mainly due to their high specific strength, low cost, resistance to corrosion, ease of manufacturing, and flexibility in design [1]. Such excellent properties have made it possible for these materials to be used in automobiles, aircraft, marine vessels, bulletproof jackets, electric and electronic components [2]. PMCs can be described as multiphase material wherein one of the phases is the polymer matrix and the other is the reinforcement. The continuous phase, i.e., the matrix can be either thermoplastic such as polyethylene (PE), polycarbonate (PC), polypropylene (PP) or they may be thermosetting like epoxy, ureas, and polyesters, etc. There are several techniques to develop PMCs including but not limited to, hand lay-up, vacuum infusion, pultrusion, resin injection molding, and compression molding. The dispersed phase which is the reinforcement may be in the form of particulates and fibers [3] .

The particulate reinforcements are sometimes even referred to as reinforcing fillers, which are inert in nature, that are used to make the material more cost-effective while enhancing the mechanical properties and overall performance of the composites [4]. The enhancement in the properties of filler reinforced composites depends on their intended function and some other parameters such as size (for example nano [5]), interactions, and loading. The particle size of the filler is a crucial determinant in discussions on the processing and properties of PMCs [6].

In response to the growing concern regarding the sustainability of these materials, bio-based fillers are being considered as potential replacements for their synthetic counterparts. Apart from being biodegradable, they are also cheaper, less dense, and have high specific strength. The most common bio-fillers used presently are produced from agricultural waste like soy protein, coconut husk, sugarcane bagasse, and also from various shell powders [7, 8]. The use of shell powders as reinforcing fillers in polymers has received significant traction in the last decade. In the past, the influence of treated and untreated Portunus sanguinolentus shell powder on the thermo-mechanical properties of jute fabric/epoxy composites has been studied. The results showed that the $10 \mathrm{wt} \%$ treated shell powder composites had the best overall performance [9]. Some studies have also been taken up as an application-oriented research, for example, the potential of silane-treated shell powders as reinforcement for phenolic brake friction composites [10].

Periwinkle (Littorina littorea) is a type of sea snail having hard shells whose hardness can be attributed to the presence of calcium carbonate [11]. HDPE combined with inorganic particulate fillers is a promising field of research as they can be made valuable in many industrial applications mainly owing to its ease of processing [12].

The potential of PSP as a reinforcing filler is yet to be fully determined as only few studies have been published so far. The results of the investigations using PSP as filler have shown a noteworthy rise in mechanical properties of the developed composites [13, 14]. However, the use of PSP in HDPE composites has not been reported yet. A composite of this type will be ideal for reducing the almost non-biodegradable portion in HDPE composite-based material and in the way help in the reduction of environmental problems. In the present study, novel PHPC samples were developed with varying particle sizes of PSP. The weight fraction of the filler was kept constant, as the main scope of the current study was to optimize the size of PSP in HDPE composites. Therefore, the weight fraction of PSP was fixed at $1 \mathrm{wt} \%$, in order to have minimal influence of filler concentration in PHPC. Morphological analysis of PHPC was done to understand the filler/composite interaction based on the filler size. 
The developed samples were subjected to thermal and mechanical tests to analyze their corresponding response. An extension evaluation method for ranking the developed composites was also reported in this study. Using the results of the tests performed, an attempt was made to provide an optimized particle size for PSP. It also gives evidence suggesting the usefulness of PSP as potential reinforcement in thermoplastic composites.

\section{MATERIALS AND METHODS}

\subsection{PSP - Size reduction}

The periwinkle shells collected from Kovalam beach, Chennai, Tamil Nadu, India, were powdered and separated based on the difference in particle size ranging from 0 to $150 \mu \mathrm{m}$ using a sieve separator. The PSPs were separated using a screening method with a Ro-Tap motorized sieve shaker, India. The various sizes include under 53 (<53 or L53) $\mu \mathrm{m}, 53 \mu \mathrm{m}, 75 \mu \mathrm{m}, 90 \mu \mathrm{m}, 105 \mu \mathrm{m}$, and $150 \mu \mathrm{m}$.

\subsection{Mixing and Compounding}

Once the PSP material was separated based on their particle size, it was then mixed with HDPE purchased from ONGC petro addition Ltd., India, having a Melt Flow Index $\mathrm{MFI}\left(190^{\circ} \mathrm{C} / 2.16 \mathrm{~kg}\right)$ of $0.04 \mathrm{~g} / 10 \mathrm{~min}$. The mixing was performed using a high shear blade mixer and 1 wt. \% PSP was incorporated into HDPE to get PSP/HDPE mixture. The mix was then compression molded at a temperature of $190( \pm 5)^{\circ} \mathrm{C}$ and pressure of $22( \pm 2) \mathrm{N} / \mathrm{mm}^{2}$ for 8 mins using a hydraulic press manufactured by Ravi Engineering work, New Delhi. During the molding process, breathing was done at $1^{\text {st }}$, $3^{\text {rd, }}$ and $5^{\text {th }}$ min to remove the water molecules and other volatile matter. Then, the mold was quenched and the composite sheets were taken out. The prepared composites for the investigation were named $\mathrm{PHPC}_{0}$ (neat HDPE), $\mathrm{PHPC}_{55}, \mathrm{PHPC}_{53}$, $\mathrm{PHPC}_{75}, \mathrm{PHPC}_{90}, \mathrm{PHPC}_{105}$, and $\mathrm{PHPC}_{150}$ based on the PSP size reinforced in it. The size of PSP beyond $150 \mu \mathrm{m}$ was not used because the coarseness of the filler resulted in mixing difficulties.

\subsection{Characterization}

\subsubsection{SEM analysis}

The chemical composition of the PSP powder was found by performing Energy-dispersive X-ray spectroscopy (EDX) analysis and the morphology of the PHPC samples was studied by SEM analysis, both using a Zeiss Sigma FESEM 500VP, Germany.

\subsubsection{Density and Void Fraction}

The Archimedes principle was used to measure the actual densities of the prepared composite samples. The density measurement was done following the standard ASTM D792, using distilled water as the liquid medium. The actual density of these samples was determined using Eq.(1). 


$$
\rho_{\mathrm{a}}=\frac{\rho_{\mathrm{w}} \mathrm{W}_{\mathrm{a}}}{\mathrm{W}_{\mathrm{a}}-\mathrm{W}_{\mathrm{w}}}
$$

where,

$\rho_{\mathrm{a}}$ is the actual density of composite, $\rho_{\mathrm{w}}$ is the density of distilled water, $\mathrm{w}_{\mathrm{w}}$ is the weight of the sample in water and, $\mathrm{w}_{\mathrm{a}}$ is the weight of the sample in the air.

The theoretical density of the composites was calculated using Eq.(2) [13],

$$
\rho_{\mathrm{t}}=\frac{1}{\left(\frac{\mathrm{w}_{\mathrm{f}}}{\rho_{\mathrm{f}}}\right)+\left(\frac{w_{\mathrm{m}}}{\rho_{\mathrm{m}}}\right)}
$$

where,

' $\rho_{\mathrm{t}}$ is the theoretical density of composite, $\rho_{\mathrm{f}}$ is the density of filler, ' $\rho_{\mathrm{m}}$ ' is the density of matrix, ' $w_{f}$ ' is the weight fraction of filler and, ' $w_{m}$ ' is the weight fraction of the matrix.

The void volume fraction ( $v v)$ percent in the composite samples was determined, [13] by Eq.(3).

$$
\mathrm{v}_{\mathrm{v}}=\frac{\left(\rho_{\mathrm{t}}-\rho_{\mathrm{a}}\right)}{\rho_{\mathrm{t}}} \times 100
$$

\subsubsection{Thermal Analysis}

The thermal properties of the PHPC samples were studied using a thermogravimetric analyzer (TA Instruments, Germany) as per the ASTM D1131 standard at a temperature range from ambient to $1000^{\circ} \mathrm{C}$ temperature with a heating rate of 10 ${ }^{\circ} \mathrm{C} / \mathrm{min}$. Nitrogen $\left(\mathrm{N}_{2}\right)$ atmosphere was maintained over the samples by flowing $\mathrm{N}_{2}$ at a flow rate of $2 \mathrm{ml} / \mathrm{min}$ while testing.

\subsubsection{Mechanical Properties}

The mechanical properties such as impact strength, tensile strength (TS), Young's modulus, elongation at break (\%), flexural strength, flexural modulus and hardness were tested for five replicates of each composite and the average values have been reported.

Tensile properties

The tensile properties of PHPC samples were found by using a 40 -ton universal testing machine (UTM) supplied by Fuel Instruments \& Engineers Pvt. Ltd, India. The test was carried out by following the ASTM D638 standard, where dog-shaped samples with $3 \mathrm{~mm}$ thickness were used. The crosshead speed was maintained at $3 \mathrm{~mm} / \mathrm{min}$.

Impact strength

Charpy impact strength of PHPC samples was measured using an Impact Tester manufactured by National Instrument, India. The testing was done with adherence to 
the ASTM D6110 standard. All samples were notched, and the measurement was carried out.

Flexural properties

The flexural properties of PHPC samples were determined by using a three-point loading method as per the ASTM D790 standard [14]. A 40-ton UTM supplied by Fuel Instruments \& Engineers Pvt. Ltd, India was used to conduct the flexural test.

Hardness

The hardness of the prepared samples was measured using a Shore-D durometer manufactured by PolyPlast Equipment \& Accessories, India. The testing was done according to the ISO 868 standard.

\section{RESULTS AND DISCUSSION}

\subsection{EDX analysis of PSP}

EDX is a characterization technique used to determine the purity and stoichiometry of compounds [15]. Table 1 contains the EDX data for the composition of PSP. Calcium was majorly present in PSP constituting a normalized weight \% of 80.28 followed by carbon constituting 16.94. The atomic \% of calcium and carbon was found out to be 57.64 and 40.58 respectively. These results show that the PSP is mainly made up of calcium as depicted in Figure 1. Aluminum is present in the lowest quantity with $0.29 \%$ by weight and $0.31 \%$ by atomic concentration.

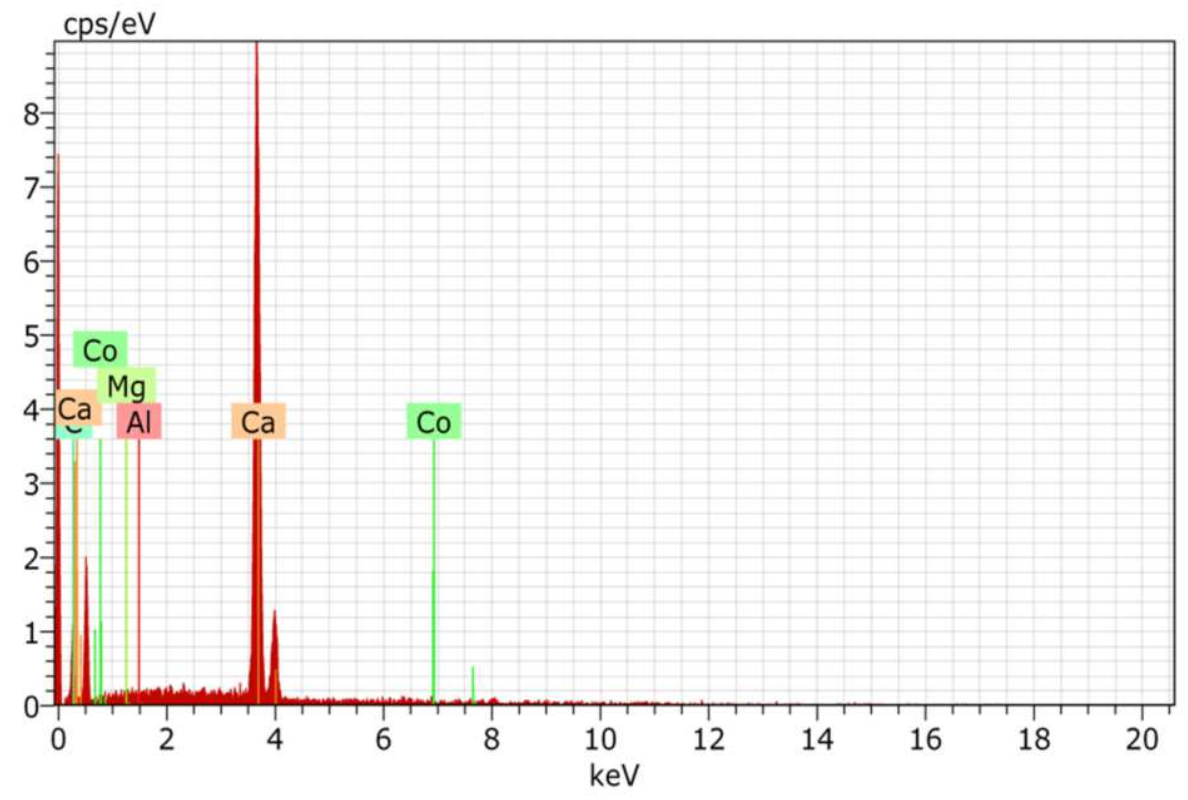

Fig. 1. EDX spectrum of the chemical composition of PSP 
Table 1.Composition of PSP using EDX

\begin{tabular}{ccc}
\hline Element & Weight \% & Atomic \% \\
\hline Calcium & 80.28 & 57.64 \\
Carbon & 16.94 & 40.58 \\
Cobalt & 2.14 & 1.04 \\
Magnesium & 0.36 & 0.42 \\
Aluminum & 0.29 & 0.31 \\
Total & 100.00 & 100.00 \\
\hline
\end{tabular}

\subsection{Density and Void Fraction of Composites}

As the filler loading was the same for all the filled samples, the theoretical density, experimental or actual density, and void fraction was calculated for PHPC 0 and PHPC $_{150}$. The actual density of PHPC 0 and $\mathrm{PHPC}_{150}$ was found to be 0.949 and 1.005 $\mathrm{g} / \mathrm{cc}$, respectively. This increase in the density of PHPC ${ }_{150}$ can be attributed to the presence of filler. The theoretical density, as expected, was higher with the values $0.952 \mathrm{~g} / \mathrm{cc}$ for $\mathrm{PHPC}_{0}$ and 1.011 for $\mathrm{PHPC}_{150}$, than the actual density due to the presence of voids, which may have formed during composite preparation. The void fraction was calculated to be $0.525 \%$ and $0.593 \%$ for PHPC 0 and PHPC 150 respectively.

\subsection{Morphology - SEM Analysis}

Figure 2 represents the micrographs of the cross-section of PHPC samples at the magnification of $500 \mathrm{X}$ and $5000 \mathrm{X}$. These images confirmed the agglomeration of PS particles in $\mathrm{PHPC}_{75}$, whereas PSP was found to be well dispersed within the HDPE matrix when the particle size is $150 \mu \mathrm{m}$. Also, the PS particles were found to have an irregular shape. The absence of particulate filler in PHPC 0 was confirmed by the SEM micrographs (Figure 2a). At 500 X magnification, the PHPC 75 sample vividly displayed clusters of PS particles due to the agglomeration. The interface between the HDPE and PSP may have decreased resulting in the agglomeration of the PSP particles which can be observed at $5000 \times$ (Figure 2b). A similar observation was made while studying the morphology of HDPE composites reinforced with marble and granite dust [16]. In the case of PHPC ${ }_{150}$, good dispersion of PSP was observed, and the particles were embedded into the HDPE matrix (Figure 2c). Although parts of the PSP surface could be seen attached to the matrix at both sizes, it was more profound in the case of $150 \mu \mathrm{m}$. Therefore, enhanced mechanical anchoring for the particulate filler could be detected for PHPC ${ }_{150}$. This phenomenon was also reported by researchers studying the SEM micrographs of mollusk shell-filled HDPE composites [12]. As inferred, the size of the particulate filler has an important role in determining interactions between two or more components [17]. 

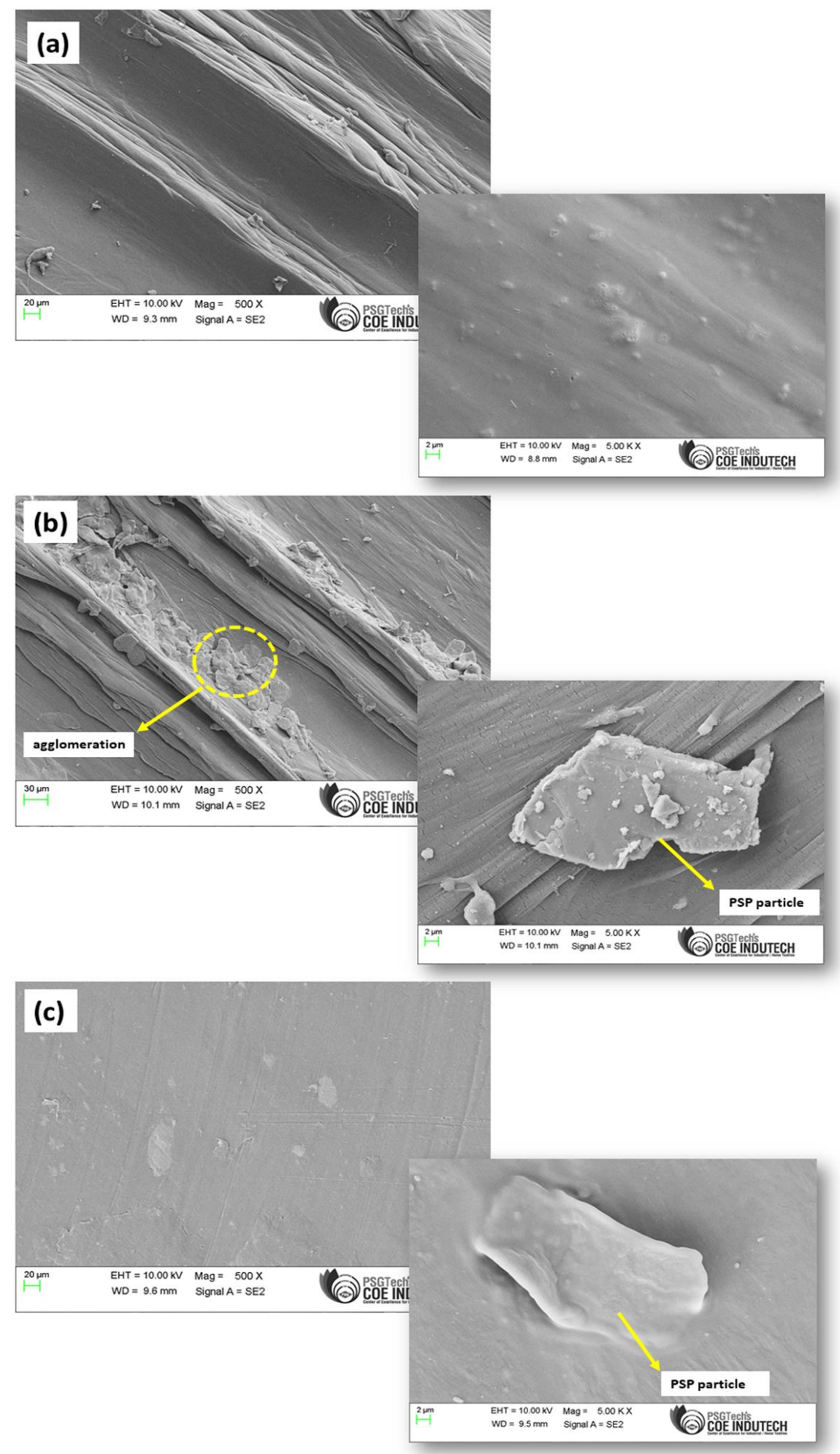

Fig. 2. SEM images of PHPC cross-section at magnifications of $500 \mathrm{X}$ and 5000 $\mathrm{X}$ (a) $\mathrm{PHPC}_{0}$, (b)PHPC 75 and (c) $\mathrm{PHPC}_{150}$ 


\subsection{Thermal Analysis}

Thermogravimetric analysis (TGA) was done to determine the thermal stability of the polymer composites. The change in weight of the sample was measured as a function of increasing temperature [18]. Figure 3 depicts the thermograms of seven samples and Figure 4 depicts the respective first derivative curve as a function of temperature in the $\mathrm{N}_{2}$ atmosphere.

Table 2 shows the values of $T_{\max }$ which is the temperature at maximum weight loss rate (peak of the first derivative curve), the weight loss \%, and residue in milligram $(\mathrm{mg})$ at near $500^{\circ} \mathrm{C}$. All samples were found to undergo single-stage decomposition. The first derivative peak temperature, which is the point of the greatest rate of change on the weight loss curve, was fairly similar for all the samples. This indicates that PSP had little influence over the thermal stability of the material, except for the PHPC ${ }_{150}$ sample. An approximate $4.1^{\circ} \mathrm{C}$ rise in $\mathrm{T}_{\max }$ was noticed for this composite, hence establishing the role of PSP in the enhancement of its thermal stability. This particular phenomenon can be explained based on the good dispersion of PSP particles within the HDPE matrix which leads to the diffusion of volatile decomposition products being hindered resulting in the creation of carbonaceous char. Therefore, the PS particles were observed to have a physical barrier effect, obstructing heat diffusion and impeding the degradation of the volatiles from the PHPC ${ }_{150}$. A similar inference was made by studying the thermal properties of nano $\mathrm{CaCO}_{3}$ reinforced polypropylene composites [19]. Another indication of greater char production for PHPC ${ }_{150}$ could be related to the comparatively higher residue obtained from its thermal decomposition.

High weight loss \% and the proportionately low residue were due to low inorganic content and absence of aromatic rings in the samples. Such observations have been made earlier by other researchers $[22,23]$.

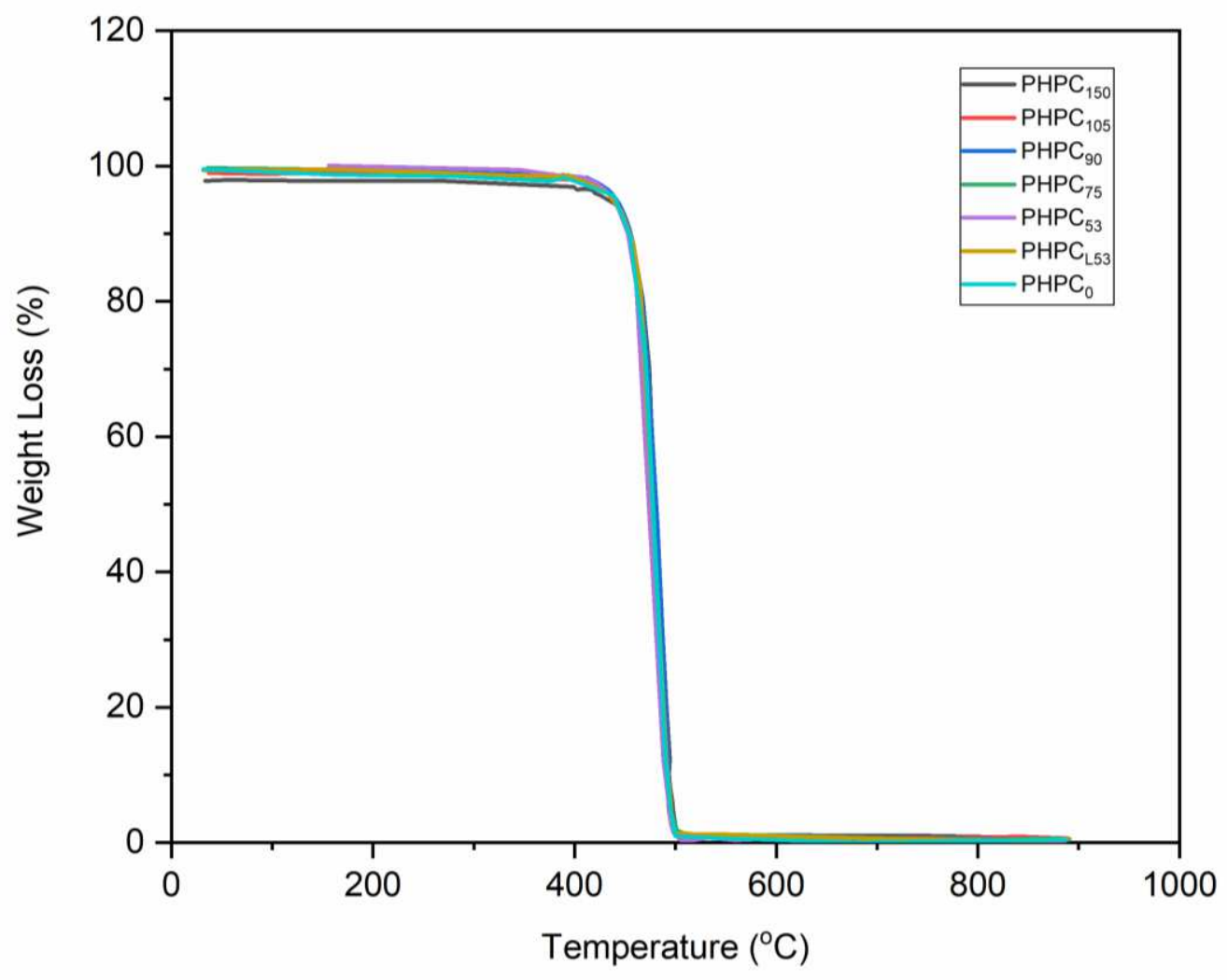

Fig. 3. TGA curves of PHPC samples 


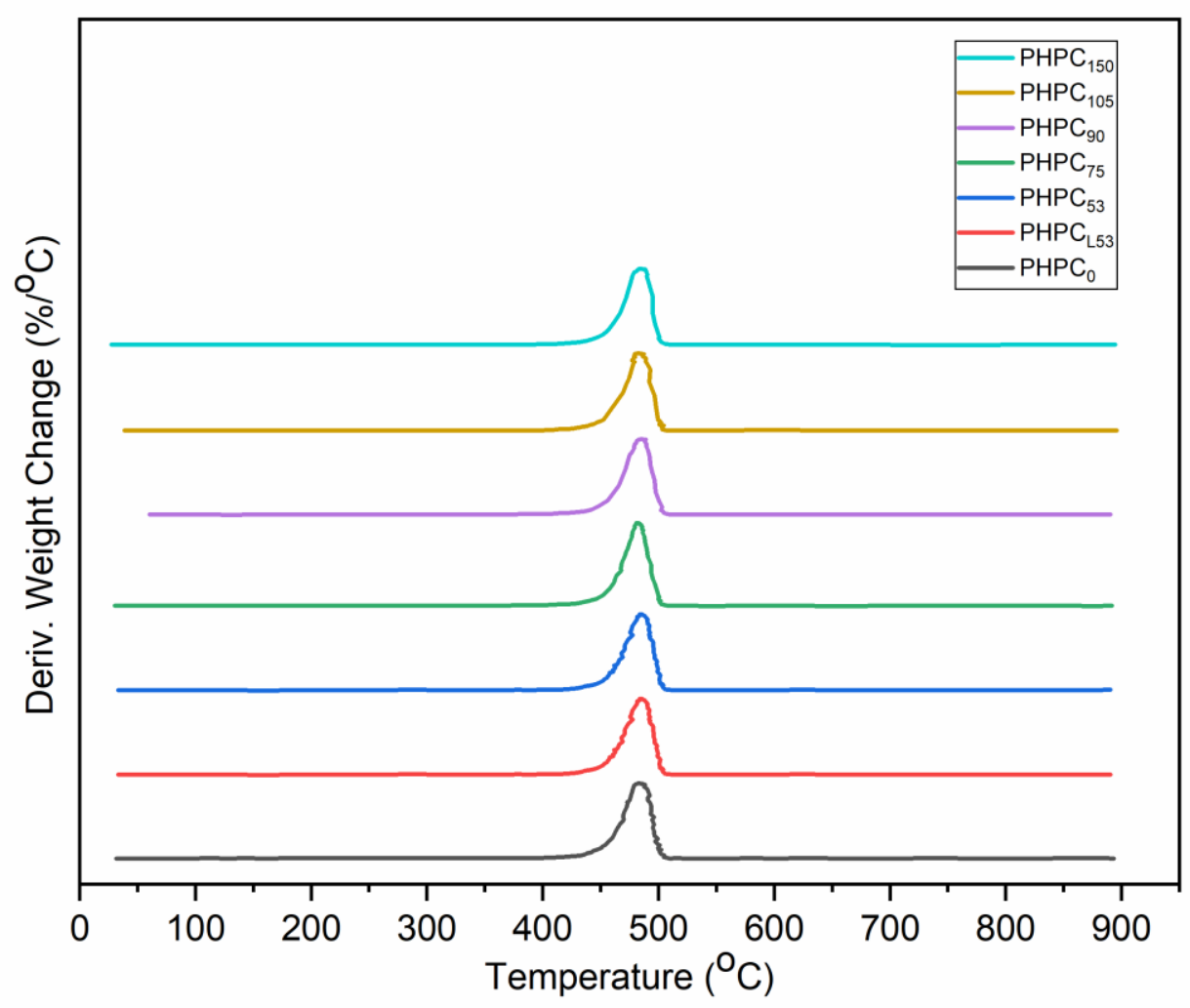

Fig. 4. First derivative curve of PHPC samples

Table 2. Thermal decomposition data of PHPC samples

\begin{tabular}{lccc}
\hline Sample & $\mathbf{T}_{\max }\left({ }^{\circ} \mathrm{C}\right)$ & $\begin{array}{c}\text { Weight Loss } \\
(\%)\end{array}$ & Residue (\%) \\
\hline PHPC $_{0}$ & 481.66 & 99.47 & 0.53 \\
PHPC $_{553}$ & 482.07 & 99.48 & 0.50 \\
PHPC $_{53}$ & 481.13 & 99.78 & 0.14 \\
PHPC $_{75}$ & 481.75 & 99.82 & 0.18 \\
PHPC $_{90}$ & 483.36 & 99.57 & 0.40 \\
PHPC $_{105}$ & 481.89 & 99.31 & 0.70 \\
PHPC $_{150}$ & 485.75 & 99.31 & 0.70 \\
\hline
\end{tabular}


The conclusion is that there is marginal increase of thermal stability with loading of PHP particles. This is obvious as with introduction of inorganic particles there are two effects:

1. Addition of high thermally stable inorganic filler enhances the resistance for thermal degradation.

2. As the size increases, the coverage of the surface increases resulting in higher barrier properties so that the gases generated from the degraded material faces more resistance to escape and thus thermal resistance is enhanced.

\subsection{Mechanical Properties}

\subsubsection{Tensile Properties}

The TS on the specimens were determined in accordance with the ASTM D 638 standard. The TS test was done to measure the tensile force required to fracture the composite samples and the elongation it possesses at the time of failure. The stress-strain curve produced was used to determine the tensile properties of the composite samples [20].

Figure 5 shows the variation of TS and Young's modulus of all PHPC samples with different PSP particle sizes. The Young's modulus values depict, that PHPC 105 (1535.54 MPa) had the highest modulus followed by other samples having lower particle sizes. A general trend can be established wherein the samples show a degradation in the modulus with the decrease in size. Compared to the neat sample, a significant rise of $112.42 \mathrm{MPa}\left(7.32 \%\right.$ increase) was documented for PHPC ${ }_{105}$, which brings forth the importance of PSP in the enhancement of the composite modulus. The reason is that, at lower size the distribution of filler is inferior when compared to the larger particle size.

Figure 6 illustrates the change in elongation at break (\%) of PHPC samples for different PSP particle sizes. The elongation at break (\%) was found to be the highest for $\mathrm{PHPC}_{0}(81.36 \%)$. Upon addition of PSP as a filler, this property was observed to have largely decreased, with the value for $\mathrm{PHPC}_{75}$ being the lowest $(28.01 \%)$. This is a clear indication of the reduced ductility of the prepared composites. It can be attributed to the hardening effect of PSP on the HDPE matrix, which is confirmed by the hardness test.

The role of fillers in enhancing Young's modulus of polymer composites while decreasing ductility has been studied in the past. A similar trend was reported upon the addition of Catla fish scales as reinforcement in polypropylene composites [21]. The addition of egg and oyster shell in HDPE and linear LDPE respectively, at all filler loadings, also resulted in increasing Young's modulus while degrading the elongation at break $(\%)[22,23]$.

Furthermore, the TS of PHPCo $(25.61 \mathrm{MPa})$ was found to be the highest, closely followed by PHPC 75 (25.53 MPa), $\mathrm{PHPC}_{105}(25.13 \mathrm{MPa}), \mathrm{PHPC}_{150}(24.56 \mathrm{MPa}$ ), and $\mathrm{PHPC}_{90}(24.31 \mathrm{MPa})$. For smaller particle sizes, a decrease in TS was observed, with $\mathrm{PHPC}_{\mathrm{L} 53}$ and $\mathrm{PHPC}_{53}$ having values of $21.65 \mathrm{MPa}$ and $22.92 \mathrm{MPa}$, respectively. The decrease in tensile strength upon the addition of filler can be attributed to the introduction of discontinuous domains in the composite, that would act as potential stress concentrators. Similar remarks have been made in the past by researchers studying eggshell reinforced polystyrene composites [24]. 


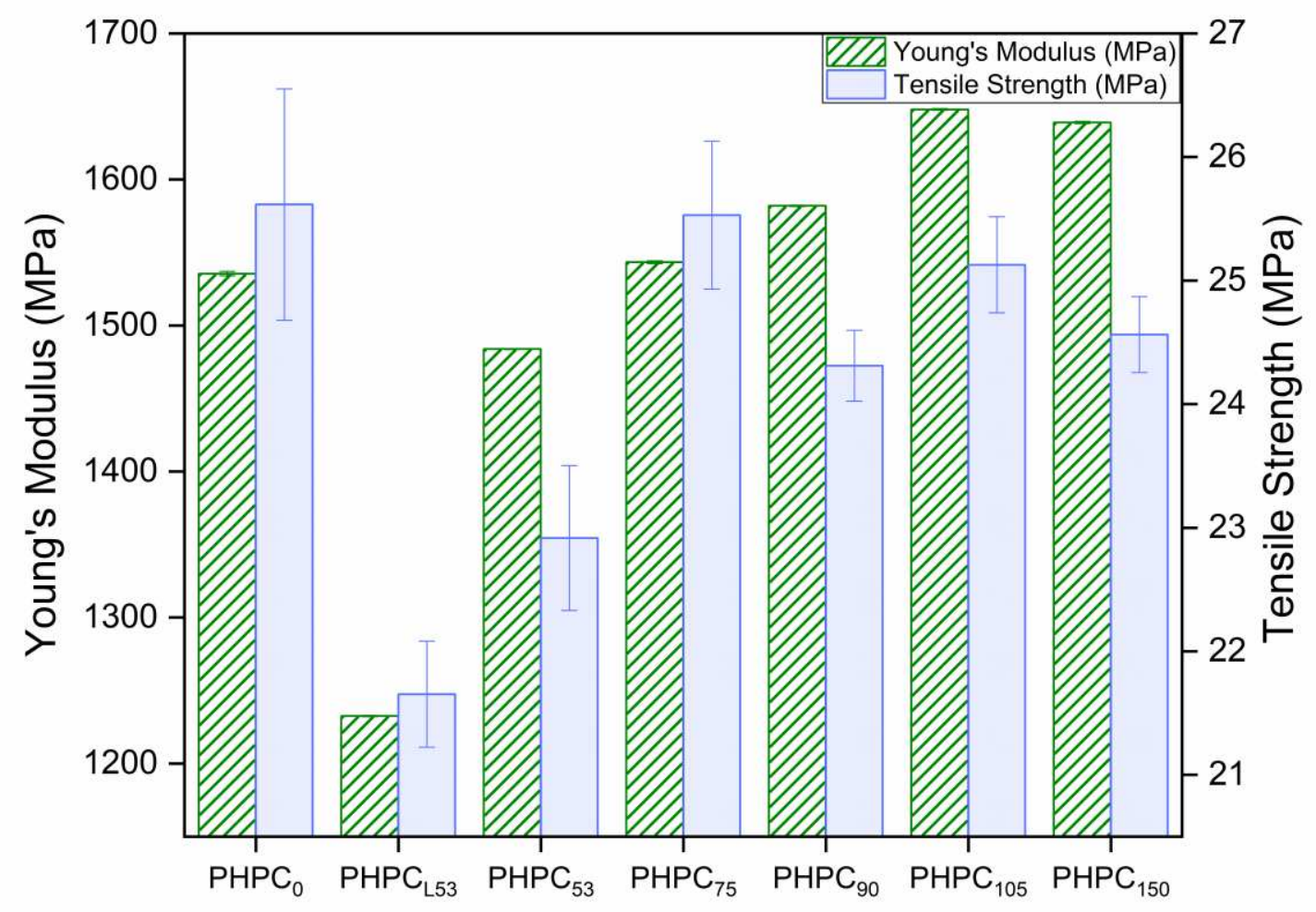

Fig. 5. Variation of TS and Young's modulus of PHPC with respect to different PSP particle sizes

After the decrease at very low filler size, there was an increase in TS with increase of size because of their better distribution in the matrix. After reaching a maximum at $75 \mu \mathrm{m}$ particle size, there was modest decrease in TS with increase of particle size. This may be because of decrease in interface area. However, the distribution being good, there was very small decrease in TS. Also in this investigation, the loading being low the difference was found to be minimum. 


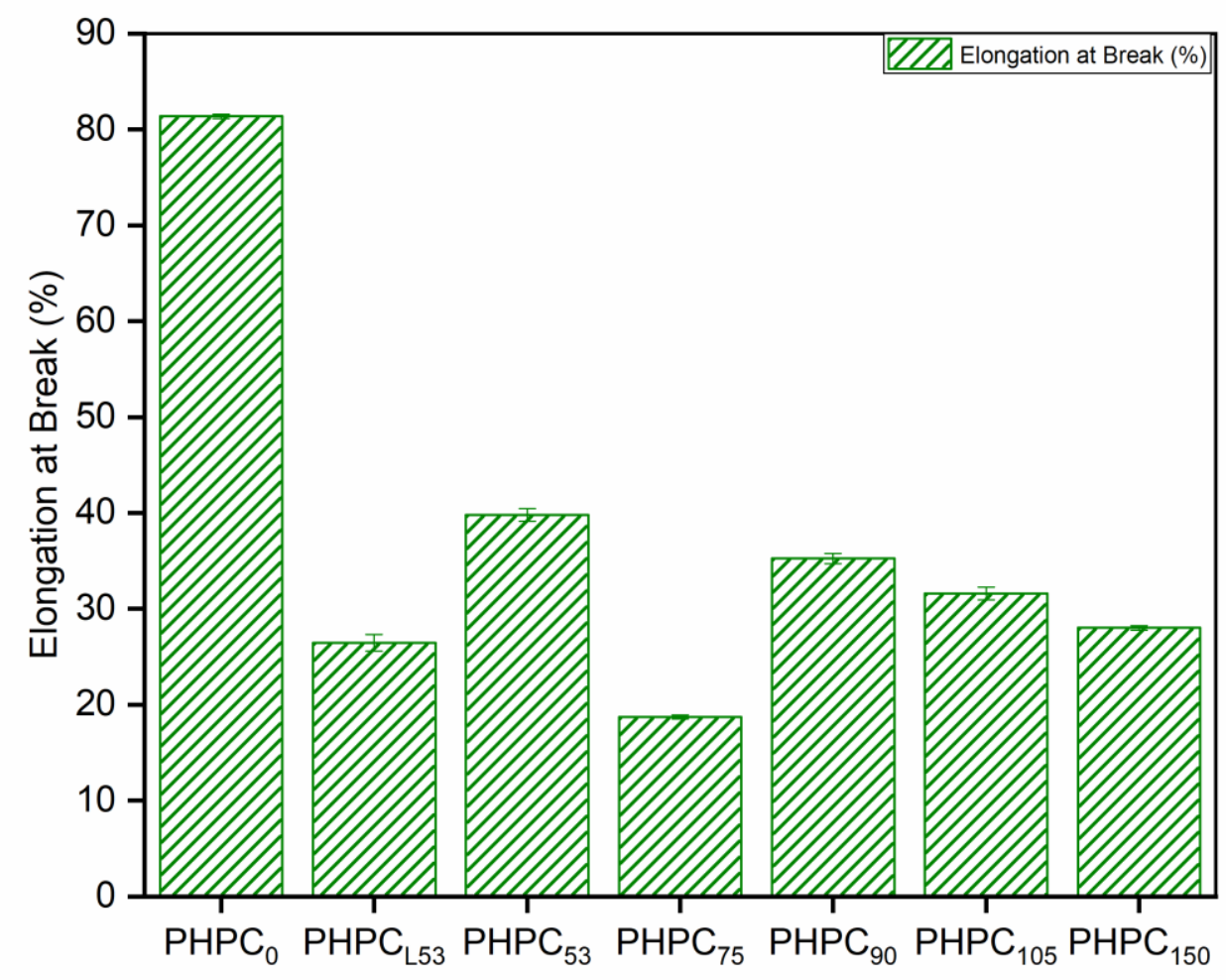

\section{Fig. 6. Variation of Elongation at break (\%) of the composites for different PSP particle sizes}

Elongation at break decreases with loading of filler of very small size. However, with further loading there is increase of elongation due to increase of void volume. With further increase of size of fillers there is not much variation due to very small amount of filler loading.

\subsubsection{Impact Strength}

The impact strength is the amount of sudden force a material can absorb before failing [25]. The effect of the particle size of the PSP on the impact strength of HDPE was studied. Figure 7 shows the impact strength of various PHPC samples. PHPC with a PSP particle size of $53 \mu \mathrm{m}$ had the best impact strength. It increased from $25.41 \mathrm{~kJ} / \mathrm{m}^{2}$ for $\mathrm{PHPC}_{0}$ to $28.61 \mathrm{~kJ} / \mathrm{m}^{2}$ for $\mathrm{PHPC}_{53}$ composite. This increase confirms the observation that more force is required to propagate the crack that is initiated while impaction. The impact strength is higher usually when the tensile stress is lesser. Both of them are inversely proportional. In other words, slower deformation over prolonged stress, causes it to absorb a greater amount of force before breaking apart [26]. In this case, it was evident as the maximum TS was almost the lowest for PHPC 53 sample (21.92 MPa). The other PHPC samples followed a similar trend except for PHPCL53 which could be an aberration. It has also been found that the lower the impact strength, the higher is the brittleness [27].

From the present investigation, it was also found that $\mathrm{PHPC}_{53}$ had better impact strength than peanut husk/HDPE, rice husk/HDPE composite, and walnut shell/HDPE 
composites [28]. Additionally, HDPE nano-composite filled with 4 wt. \% talc was reported to have lesser impact strength comparatively [29].

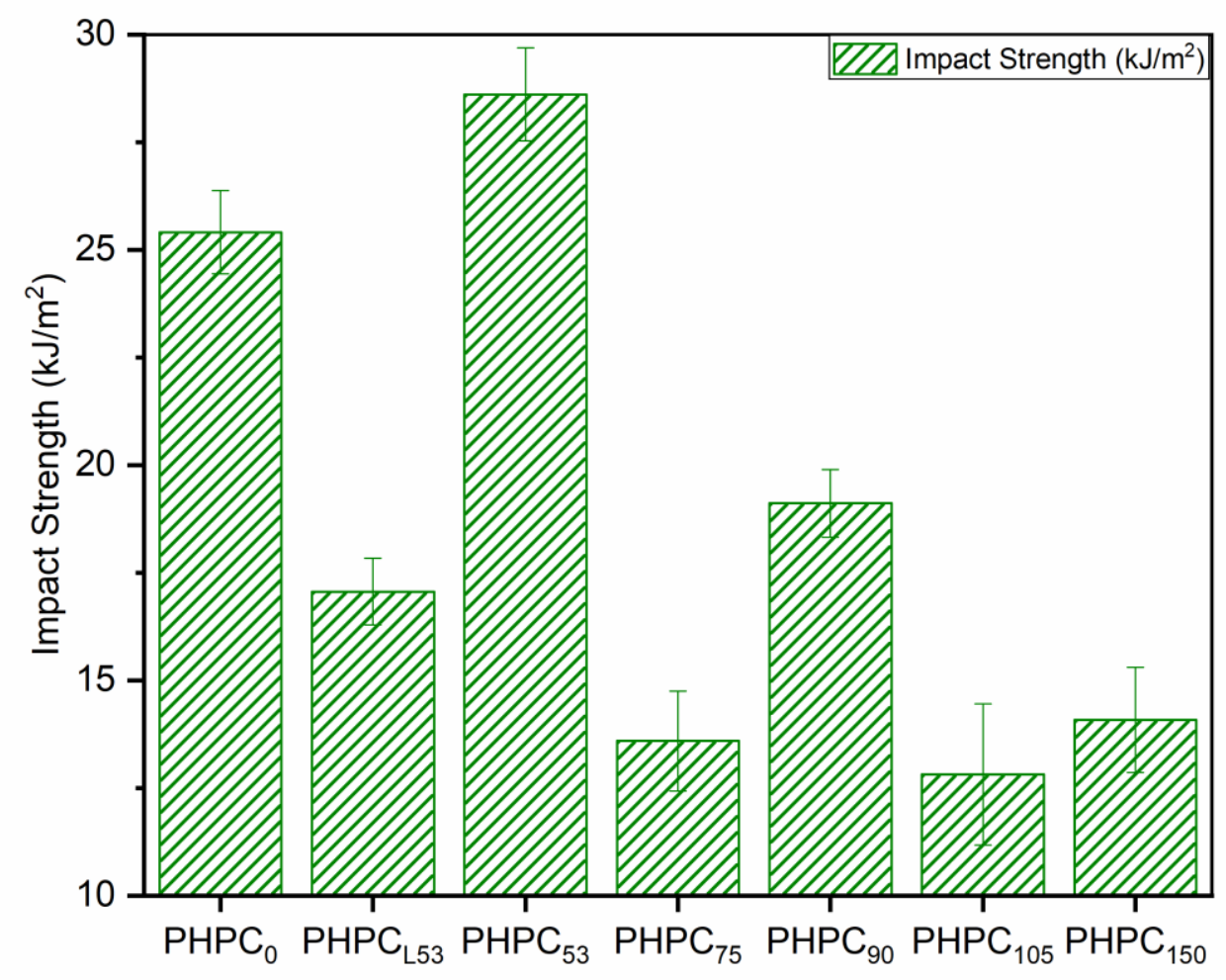

Fig. 7. Variation of Impact strength of the composites with respect to different PSP particle sizes

During the addition of lowest size PSP $(<53 \mu \mathrm{m})$ there is more of agglomeration rather than distribution, which does not help in enhancement of impact properties. Rather, it acts towards reduction of the impact characteristics of HDPE. However, with $\mathrm{PHPC}_{53}$ samples, the size is lower as compared to most of the samples. This suggests that there is increase of interface among the PSP filler and HDPE resulting in increase of impact strength. Thereafter there is decrease of impact strength, which is justified as with increase of size there is decrease of total interface area. This results in lower extent of energy transfer from the weaker component (HDPE) to the stronger component (PSP particles).

\subsubsection{Flexural properties}

When the load is applied at three points, the flexural strength of the material can be measured [14]. Figure 8 depicts the flexural strength and the flexural modulus of PHPC samples respectively. PHPC 0 had the highest flexural strength, while the lowest was observed for $\mathrm{PHPC}_{105}$ composite having a value of $28.49 \mathrm{MPa}$ and $18.91 \mathrm{MPa}$ respectively. The maximum flexural strength values for PHPC0 were followed by 90 $\mu \mathrm{m}, 150 \mu \mathrm{m}, 75 \mu \mathrm{m}, 53 \mu \mathrm{m}$, and $<53 \mu \mathrm{m}$ PS particle reinforced composites and had 
$4.1 \%, 8.4 \%, 8.8 \%, 11.6 \%$, and $20.6 \%$, lesser values with regard to the flexural strength of PHPCo respectively. The poor strength of the composites in comparison to $\mathrm{PHPC}_{0}$ can be due to poor particle-matrix debonding and easy breakage that may have occurred due to improper formation of strong bonds between the matrix and the PS particles. Similar results were reported with the use of micro-sized marble dust [30]. The higher flexural strength for PHPC $_{90}$ samples was observed when compared with the other -article sizes of PSP. This may be due to the better distribution of PSP in HDPE. Alike observation has been made formerly concerning filled polypropylene composites [31].

The flexural modulus was found to be highest for PHPC 90 composites and the least when $105 \mu \mathrm{m}$ size particle was added to HDPE corresponding to $1084.62 \mathrm{MPa}$ and $599.7 \mathrm{MPa}$, respectively. Compared to other filler reinforced HDPE composites, PHPC was found to be superior. For example, hemp fiber/HDPE composite had a flexural strength ranging from 12.27 MPa to 22.56 MPa [32]. Furthermore, the flexural strength and modulus of nano clay/HDPE nanocomposites ranged from 19.20-22.24 $\mathrm{MPa}$ and 656-735 MPa, respectively [33]. A recent study with waste tungsten carbide (WC) reinforced HDPE composites had approximate maximum and minimum flexural modulus as $750 \mathrm{MPa}$ and $850 \mathrm{MPa}$, respectively [34]. Hence, the superiority of PHPC was established in this current investigation.

In general, for PHPC samples the tensile modulus (Young's modulus) was found to be greater than the flexural modulus. This indicates that the composite samples have a higher stiffness towards tensile loading than bending (flexural loading). 


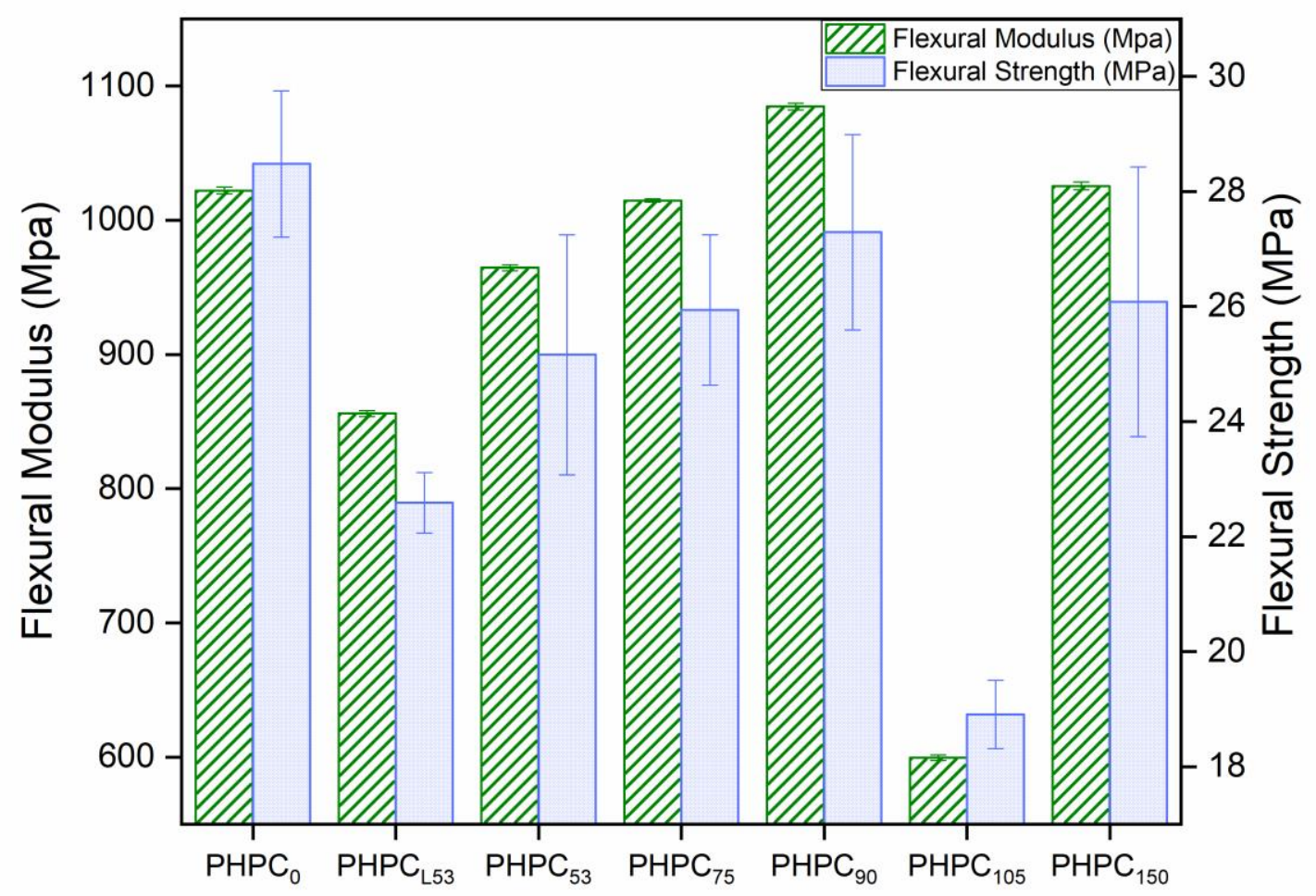

\section{Fig.8. Variation of flexural strength and flexural modulus of PHPC samples with respect to different PSP particle sizes}

As expected, there is initial decrease of flexural strength. Immediately after that there is increase of strength up to $90 \mu \mathrm{m}$ size of PSP. This is quite possible as the filler particles of larger size are distributed uniformly along the matrix. In fact it was reported that there is best distribution of inorganic particles of size $63 \mu \mathrm{m}$ [35]. With further increase of size there is decrease of the flexural strength because of decrease of interface area and also because of inferior distribution.

\subsubsection{Hardness}

The hardness of the composite sample is measured using a Shore D durometer. These values are a measure of the resistance of a material to penetration and deformation [36]. For PMCs, their hardness is mainly dependent upon the interactions present within the filler-polymer matrix interphase, filler hardness, and filler grain size [37].

Figure 9 shows the variation in hardness of PHPC samples. The addition of PSP to HDPE resulted in the enhancement of the hardness of the developed composites. This can be attributed to the introduction of the hard and brittle PSP phase into the HDPE matrix and the microstructure of the prepared composites. Similar phases have been introduced in polyester resin and HDPE matrices by hardwood charcoal particulates and coconut shell powder respectively [38, 39]. 
The reasoning for $\mathrm{PHPC}_{75}$ having the highest hardness value could be correlated with the SEM micrographs, which illustrates distinct clusters or agglomeration of the PSP particles which form hard filler grains in the composite microstructure. An approximate $9.1 \%$ increase in hardness from the lowest (PHPC) to the highest value $\left(\mathrm{PHPC}_{75}\right)$ has been recorded. Beyond that, the size does not alter the behavior; rather at same loading the value reaches a plateau. This may be due to the coverage of the surface by the filler remains similar.

All PSP reinforced samples were found to have a greater hardness than $\mathrm{PHPC}_{0}$. This is in accordance with other research work done which observed an increase in hardness upon the addition of filler [40].

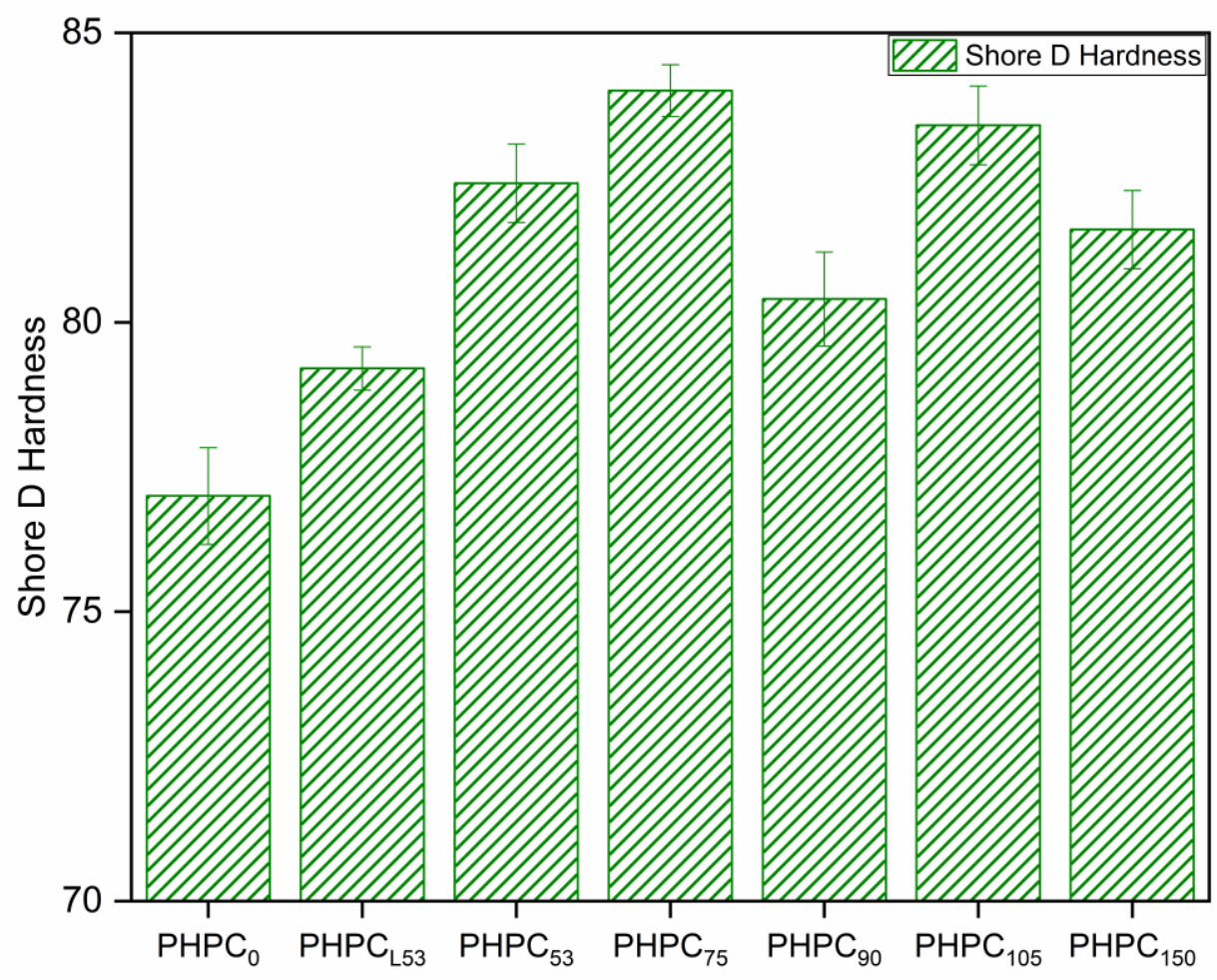

Fig.9. Variation of hardness of PHPC samples with respect to different PSP particle sizes

\subsection{Extension evaluation method for ranking polymer composites}

Based on the extension theory, the extension evaluation method (EEM) was performed to establish the non-linear relationship between the particle size of PSP filler and the mechanical performance of the composites. EEM aids in the ranking of developed composite materials and allows for the prudent selection of the best composite sample [41].

The most crucial part of developing the extension theory involves the construction of a mathematical model/dependent function $(\mathrm{K}(\mathrm{x}))$. Assume $\mathrm{M} \in \mathrm{X}$, where $X$ is an interval consisting of $X=[a, b]$. Eq. (4). defines $K(x)$ of any point within a limit $x \in[-\infty,+\infty$, conforming to the interval $X$ and the point $M$. 


$$
\mathbf{K}(\mathbf{x})= \begin{cases}\frac{\mathbf{x}-\mathbf{a}}{\mathbf{M}-\mathbf{a}}, & \mathbf{x} \leq \mathbf{M} \\ \frac{\mathbf{b}-\mathbf{x}}{\mathbf{b}-\mathbf{M}}, & \mathbf{x} \geq \mathbf{M}\end{cases}
$$

The properties of the dependent function $\mathrm{K}(\mathrm{x})$ are listed below:

- $\mathrm{K}(\mathrm{x})$ reaches a maximum value, $\mathrm{K}(\mathrm{x})=1$ at $\mathrm{x}=\mathrm{M}$

- $x \in X a n d x \neq a, b \Leftrightarrow K(x)>0$

- $\quad x \notin X$ and $x \neq a, b \Leftrightarrow K(x)<0$

Table 3 shows the model calculation for PHPC $_{150}$ with different parameters chosen for ranking the sample ranges and optimum (required) points which is common for all seven samples. The parameters chosen for evaluation can be classified as follows:

- $\quad$ The elongation at break (\%) (parameter 2: Table 3) reached its optimum point of the dependent function $\mathrm{K}(\mathrm{x})$ in the left extreme of the selected interval $\mathrm{X}$. $\mathrm{K}(\mathrm{x})$ for this parameter is calculated by using Eq. (5).

$$
\mathrm{K}(\mathrm{x})=\left\{\begin{array}{c}
\frac{\mathbf{x}-\mathbf{a}}{\mathbf{b}-\mathbf{a}}, \mathbf{x}<\mathrm{a} \\
\mathbf{0} \vee \mathbf{1}, \mathbf{x}=\mathbf{a} \\
\frac{\mathbf{b}-\mathbf{x}}{\mathbf{b}-\mathbf{a}}, \mathbf{x}>\mathbf{a}
\end{array}\right.
$$

- The remaining seven parameters were found to have reached their respective optimum point of $\mathrm{K}(\mathrm{x})$ in the right extreme of $\mathrm{X}$ and the dependent degree is calculated by using Eq. (6).

$$
K(x)=\left\{\begin{array}{c}
\frac{x-a}{b-a}, x<b \\
0 \vee 1, x=b \\
\frac{b-x}{b-a}, x>b
\end{array}\right.
$$


Table 3. EEM Model calculation for PHPC 150

\begin{tabular}{|c|c|c|c|c|c|c|c|}
\hline $\begin{array}{l}\text { Sl. } \\
\text { No. }\end{array}$ & $\begin{array}{c}\text { Parameter } \\
\text { descriptions }\end{array}$ & $\begin{array}{l}\text { Interval } \\
\mathbf{X}_{\mathbf{i}}[\mathbf{a}, \mathbf{b}]\end{array}$ & $\mathbf{M}_{\mathbf{i}}$ & $\mathbf{x}_{\mathbf{i}}$ & $\mathbf{K}\left(\mathbf{x}_{\mathbf{i}}\right)$ & $\mathbf{w}_{\mathbf{i}}$ & $\overline{\mathbf{K}\left(\mathbf{x}_{\mathbf{i}}\right)}$ \\
\hline 1 & $\begin{array}{l}\text { Impact } \\
\text { Strength }\end{array}$ & $\begin{array}{l}{[12.81,} \\
28.61]\end{array}$ & 28.61 & 14.08 & 0.08 & $1 / 8$ & 0.772 \\
\hline 2 & $\begin{array}{l}\text { Elongation at } \\
\text { Break (\%) }\end{array}$ & $\begin{array}{c}{[18.705,8} \\
1.359]\end{array}$ & 18.705 & 28.011 & 0.851 & $1 / 8$ & \\
\hline 3 & $\begin{array}{l}\text { Young's } \\
\text { Modulus }\end{array}$ & $\begin{array}{c}{[1232.528} \\
\text { 1647.968] }\end{array}$ & 1647.968 & 1639.049 & 0.978 & $1 / 8$ & \\
\hline 4 & $\begin{array}{l}\text { Max. Tensile } \\
\text { Stress }\end{array}$ & $\begin{array}{l}{[21.652} \\
25.616]\end{array}$ & 25.616 & 24.563 & 0.734 & $1 / 8$ & \\
\hline 5 & $\begin{array}{l}\text { Flexural } \\
\text { Modulus }\end{array}$ & $\begin{array}{l}{[599.7} \\
1084.62]\end{array}$ & 1084.62 & 1025.54 & 0.878 & $1 / 8$ & \\
\hline 6 & Hardness & {$[77,84]$} & 84 & 81.6 & 0.657 & $1 / 8$ & \\
\hline 7 & $\begin{array}{l}\text { Residue } \\
\text { (TGA) }\end{array}$ & $\begin{array}{c}{[0.020,} \\
0.2]\end{array}$ & 0.2 & 0.2 & 1 & $1 / 8$ & \\
\hline 8 & $\begin{array}{l}\text { Peak } \\
\text { Temperature } \\
\text { (TGA) }\end{array}$ & $\begin{array}{l}{[481.13,} \\
485.75]\end{array}$ & 485.75 & 485.75 & 1 & $1 / 8$ & \\
\hline
\end{tabular}

The various variables used for calculation using EEM are as follows:

i $\quad \rightarrow$ parameter number (1-8),

$\mathrm{x}_{\mathrm{i}} \rightarrow$ measured parameter value of the sample,

$\mathrm{M}_{\mathrm{i}} \rightarrow$ optimum point of the $\mathrm{x}_{\mathrm{i}}$

$\mathrm{K}\left(\mathrm{x}_{\mathrm{i}}\right) \rightarrow$ dependent degree,

$\mathrm{w}_{\mathrm{i}} \rightarrow$ parameter weights,

$\overline{\mathrm{K}\left(\mathrm{x}_{\mathrm{i}}\right)} \rightarrow$ mean of $\mathrm{K}\left(\mathrm{x}_{\mathrm{i}}\right)$ based on Eq. (6)

Table 3 shows the model EEM calculation for PHPC $_{150}$

Eq. (7). weighs all parameters equally as each one of these criteria are important factors for evaluating the performance of the PHPC composite samples.

$$
\mathrm{w}_{1}=\mathrm{w}_{2}=\mathrm{w}_{3}=\mathrm{w}_{4}=\mathrm{w}_{5}=\mathrm{w}_{6}=\mathrm{w}_{7}=\mathrm{w}_{8}=\frac{1}{8}
$$

The weighted mean required to calculate the overall performance of the PHPC samples is calculated using Eq. (8).

$$
\overline{\mathrm{K}(\mathrm{x})}=\sum_{\mathrm{i}=1}^{11} \mathrm{w}_{\mathrm{i}} \mathrm{K}\left(\mathrm{x}_{\mathrm{i}}\right)
$$

The EEM results of all PHPC samples are shown in Table 4. 
Table 4.Results of extension evaluation for all PHPC samples

\begin{tabular}{cccccccc}
\hline $\begin{array}{c}\text { Dependent } \\
\text { Degree }\end{array}$ & PHPC $_{0}$ & PHPC $_{53}$ & PHPC $_{53}$ & PHPC $_{75}$ & PHPC $_{90}$ & PHPC $_{105}$ & PHPC $_{150}$ \\
\hline $\mathbf{K}\left(\mathbf{x}_{1}\right)$ & 0.797 & 0.268 & 1 & 0.049 & 0.398 & 0 & 0.08 \\
$\mathbf{K}\left(\mathbf{x}_{2}\right)$ & 0 & 0.876 & 0.663 & 1 & 0.735 & 0.794 & 0.851 \\
$\mathbf{K}\left(\mathbf{x}_{3}\right)$ & 0.729 & 0 & 0.605 & 0.748 & 0.841 & 1 & 0.978 \\
$\mathbf{K}\left(\mathbf{x}_{4}\right)$ & 1 & 0 & 0.319 & 0.978 & 0.670 & 0.876 & 0.734 \\
$\mathbf{K}\left(\mathbf{x}_{5}\right)$ & 0.871 & 0.528 & 0.752 & 0.855 & 1 & 0 & 0.878 \\
$\mathbf{K}\left(\mathbf{x}_{\mathbf{6}}\right)$ & 0 & 0.314 & 0.771 & 1 & 0.485 & 0.914 & 0.657 \\
$\mathbf{K}\left(\mathbf{x}_{7}\right)$ & 0.222 & 0.333 & 0 & 0 & 0.333 & 0.444 & 1 \\
$\mathbf{K}\left(\mathbf{x}_{\mathbf{8}}\right)$ & 0.114 & 0.203 & 0 & 0.155 & 0.482 & 0.164 & 1 \\
\hline $\mathbf{K}(\mathbf{x})$ & 0.466 & 0.315 & 0.513 & 0.598 & 0.618 & 0.524 & 0.772 \\
\hline
\end{tabular}

The result of this computation was used in the ranking of seven PHPC samples based on their overall performance. The best performing sample has the highest weighted mean, while the worst one has the lowest weighted mean. Ranking from best to worst is as follows:

$$
\begin{gathered}
\text { PHPC }_{150}(0.772)>\text { PHPC }_{90}(0.618)>\operatorname{PHPC}_{75}(0.598)>P^{(0.513)>} \\
\operatorname{PHPC}_{0}(0.466)>\text { PHPC }_{553}(0.315)
\end{gathered}
$$

It can be inferred from this evaluation that $\mathrm{PHPC}_{150}$ is the most preferable, while $\mathrm{PHPC}_{\mathrm{L} 53}$ is the least preferable sample for high strength, low flexibility applications. The experimental results show and confirm that the developed composites may be applied in automotive body and chassis part fabrication [42].

\section{CONCLUSION}

This study confirms the effectiveness of PSP as reinforcement in PHPC. The particle size of the filler (PSP) was varied while the filler loading was kept constant (1 wt\%). This was done to understand better the influence of the particle size of PSP on the properties of developed PHPC samples. PHPC sheets were successfully prepared by compression molding, and were subjected to different thermal, mechanical and morphological analysis. The cross-sectional SEM micrographs of the PHPC samples were carefully examined and it was found out that filler agglomeration was observed for $75 \mu \mathrm{m}$ PSP particles. Whereas, PSP particles of $150 \mu \mathrm{m}$ showed excellent dispersion in the HDPE matrix. The outcome of SEM analysis providedsignificant 
support in expounding upon the results of the hardness test in which PHPC 75 was found to have the highest hardness with a value of 84 shore D. The efficiency of PSP as a reinforcing filler was further bolstered by the various mechanical tests which showed promising results upon the incorporation of PSP. The Young's modulus of $\mathrm{PHPC}_{105}$ was approximately $112 \mathrm{MPa}$ greater than the neat sample (PHPCo), while the flexural modulus was around $62 \mathrm{MPa}$ higher for $\mathrm{PHPC}_{90}$ with respect to $\mathrm{PHPC}_{0}$. In terms of thermal stability, a marked increase of $4.1^{\circ} \mathrm{C}$ in $\mathrm{T}_{\max }$ was observed for $\mathrm{PHPC}_{150}$ sample with regard to $\mathrm{PHPC}_{0}$. Finally, the ranking of composites using the extension evaluation method helped in choosing the best performing composite, which in this case was PHPC $_{150}$. The developed composites exhibited high strength at low weight and hence could be used in the automobile sectors. The eco-friendly attribute associated with PSP made it an excellent filler for HDPE composites.

\section{REFERENCE}

1. Asim M, Saba N, Jawaid M, Nasir M (2018) Potential of natural fiber/biomass filler-reinforced polymer composites in aerospace applications. Elsevier Ltd

2. Sinha AK, Narang HK, Bhattacharya S (2020) Mechanical properties of hybrid polymer composites: a review. Journal of the Brazilian Society of Mechanical Sciences and Engineering 42:. https://doi.org/10.1007/s40430-020-02517-w

3. Goda K, Sreekala MS, Malhotra SK, et al (2013) Advances in polymer composites: Biocomposites-state of the art, new challenges, and opportunities. Polymer Composites, Biocomposites 3:1-10. https://doi.org/10.1002/9783527674220.ch1

4. Jagadeesh P, Thyavihalli Girijappa YG, Puttegowda M, et al (2020) Effect of natural filler materials on fiber reinforced hybrid polymer composites: An Overview. Journal of Natural Fibers 00:1-16. https://doi.org/10.1080/15440478.2020.1854145

5. Ratna D, Divekar S, Samui AB, et al (2006) Poly(ethylene oxide)/clay nanocomposite: Thermomechanical properties and morphology. Polymer 47:4068-4074. https://doi.org/10.1016/j.polymer.2006.02.040

6. Pegoretti A, Dorigato A (2019) Polymer Composites: Reinforcing Fillers

7. Mokhothu TH, John MJ (2017) Bio-based fillers for environmentally friendly composites. Handbook of Composites from Renewable Materials 1-8:243-270. https://doi.org/10.1002/9781119441632.ch10

8. Valsadwala AS, R. Mahesavaran, Yuvaraj A, et al (2020) Recover and Reuse of Eco-benign Filler in Flexible Polyurethane Foam. 58

9. Kumaran P, Mohanamurugan S, Madhu S, et al (2020) Investigation on thermo-mechanical characteristics of treated/untreated Portunus sanguinolentus shell powder-based jute fabrics reinforced epoxy composites. Journal of Industrial Textiles 50:427-459. https://doi.org/10.1177/1528083719832851 
10. Rajan BS, Balaji MAS, Mohamed Aslam Noorani AB (2019) Effect of silane surface treatment on the physico-mechanical properties of shell powder reinforced epoxy modified phenolic friction composite. Materials Research Express 6:. https://doi.org/10.1088/2053-1591/ab0ca5

11. Orji BO, Igbokwe GE, Anagonye CO, Modo EU (2017) Chemical Content of the Periwinkle Shell and its Suitability in Thin layer Chromatography. International Journal of Chemistry Studies 2:9-11

12. Melo PMA, MacÊdo OB, Barbosa GP, et al (2019) High-density polyethylene/mollusk shell-waste composites: Effects of particle size and coupling agent on morphology, mechanical and thermal properties. Journal of Materials Research and Technology 8:1915-1925. https://doi.org/10.1016/j.jmrt.2019.01.008

13. Evans JT (1992) Analysis and performance of fiber composites (second edition)

14. Khan SM, Malik SA, Gull N, et al (2019) Fabrication and modelling of the macro-mechanical properties of cross-ply laminated fibre-reinforced polymer composites using artificial neural network. Advanced Composite Materials 28:409-423. https://doi.org/10.1080/09243046.2019.1573448

15. Khatua L, Das SK (2020) Energy dispersive X-ray spectroscopy study of compound semiconductor zinc orthotitanate prepared by solid state reaction method. Materials Today: Proceedings 33:5628-5631. https://doi.org/10.1016/j.matpr.2020.03.794

16. Awad AH, El-Gamasy R, Abd El-Wahab AA, Abdellatif MH (2020) Assessment of mechanical properties of HDPE composite with addition of marble and granite dust. Ain Shams Engineering Journal 11:1211-1217. https://doi.org/10.1016/j.asej.2020.02.001

17. Samal S (2020) Effect of shape and size of filler particle on the aggregation and sedimentation behavior of the polymer composite. Powder Technology 366:4351. https://doi.org/10.1016/j.powtec.2020.02.054

18. Polat S, Sayan P (2020) Assessment of the thermal pyrolysis characteristics and kinetic parameters of spent coffee waste: a TGA-MS study. Energy Sources, Part A: Recovery, Utilization and Environmental Effects 00:1-14. https://doi.org/10.1080/15567036.2020.1736693

19. Kamal M, Sharma CS, Upadhyaya P, et al (2012) Calcium carbonate (CaCO3) nanoparticle filled polypropylene: Effect of particle surface treatment on mechanical, thermal, and morphological performance of composites. Journal of Applied Polymer Science 124:2649-2656. https://doi.org/10.1002/app.35319

20. Saba N, Jawaid M, Sultan MTH (2018) An overview of mechanical and physical testing of composite materials. Elsevier Ltd

21. Aradhyula TV, Bian D, Reddy AB, et al (2020) Compounding and the mechanical properties of catla fish scales reinforced-polypropylene compositefrom biowaste to biomaterial. Advanced Composite Materials 29:115-128. 
https://doi.org/10.1080/09243046.2019.1647981

22. Nwanonenyi SC, Obidiegwu MU, Onuchukwu TS, Egbuna IC (2013) Studies on the properties of linear low density polyethylene filled oyster shell powder. The International Journal Of Engineering And Science 2:42

23. Murugan S, Munusamy $Y$, Muniandy M, Ismail H (2018) Development of HDPE-modified eggshell composite. Polymer Composites 39:1630-1637. https://doi.org/10.1002/pc.24108

24. Hayeemasae N, Song LW, Ismail H (2019) Sustainable use of eggshell powder in the composite based on recycled polystyrene and virgin polystyrene mixture. International Journal of Polymer Analysis and Characterization 24:266-275. https://doi.org/10.1080/1023666X.2019.1567089

25. Graupner N, Kühn N, Müssig J (2021) Influence of sample thickness, curvature and notches on the Charpy impact strength - An approach to standardise the impact strength of curved test specimens and biological structures. Polymer Testing 93:106864. https://doi.org/10.1016/j.polymertesting.2020.106864

26. Qiu B, Qi P, Qian Z, et al (2020) Regulation on dual-interface of core-shell dispersed phases and mechanical properties of PP blends by rotary evaporation-assisted melt grafted EPDM-g-MAH. Composites Part C: Open Access 3:100065. https://doi.org/10.1016/j.jcomc.2020.100065

27. Wang W, Zhang X, Mao Z, Zhao W (2019) Effects of gamma radiation on the impact strength of polypropylene (PP)/high density polyethylene (HDPE) blends. Results in Physics 12:2169-2174. https://doi.org/10.1016/j.rinp.2019.02.020

28. Zhang Q, Li Y, Cai H, et al (2019) Properties comparison of high density polyethylene composites filled with three kinds of shell fibers. Results in Physics 12:1542-1546. https://doi.org/10.1016/j.rinp.2018.09.054

29. Chen $\mathrm{N}$, Ma L, Zhang $\mathrm{T}$ (2006) Investigation of nano-talc as a filling material and a reinforcing agent in high density polyethylene (HDPE). Rare Metals 25:422425. https://doi.org/10.1016/S1001-0521(07)60117-X

30. Sharma A, Choudhary M, Agarwal P, et al (2020) Effect of micro-sized marble dust on mechanical and thermo-mechanical properties of needle-punched nonwoven jute fiber reinforced polymer composites. Polymer Composites 1-18. https://doi.org/10.1002/pc.25873

31. Shah A ur R, Prabhakar MN, Wang H, Song J-I (2018) The influence of particle size and surface treatment of filler on the properties of oyster shell powder filled polypropylene composites. Polymer Composites 39:2420-2430. https://doi.org/10.1002/pc.24225

32. Singh S, Deepak D, Aggarwal L, Gupta VK (2014) Tensile and Flexural Behavior of Hemp Fiber Reinforced Virgin-recycled HDPE Matrix Composites. Procedia Materials Science 6:1696-1702. https://doi.org/10.1016/j.mspro.2014.07.155 
33. Beesetty P, kale A, Patil B, Doddamani M (2020) Mechanical behavior of additively manufactured nanoclay/HDPE nanocomposites. Composite Structures 247:112442. https://doi.org/10.1016/j.compstruct.2020.112442

34. Kaya N, Atan E, Sütçü M (2020) Investigation of Thermal Properties of Waste Tungsten Carbide (WC) loaded HDPE Matrix. Materials Today Communications 25:101547. https://doi.org/10.1016/j.mtcomm.2020.101547

35. Obasi HC, Mark UC, Mark U (2021) Improving the mechanical properties of polypropylene composites with coconut shell particles. Composites and Advanced Materials 30:263498332110074. https://doi.org/10.1177/26349833211007497

36. Srinivasan S, Saifee A, Begum SS, Baran A (2021) Experimental investigation on the influence of novel catalyst in co-pyrolysis of polymeric waste: Characterization of oil and preparation of char reinforced composites. Journal of Cleaner Production 316:128225. https://doi.org/10.1016/j.jclepro.2021.128225

37. Nwokoye JN, Oyom PO, llodigwe CB (2018) Effects of Snail Shell Powder on the Mechanical Properties of Low Density Polyethylene ( LDPE ). 18:

38. Obiukwu OO, Uchechukwu, M. NNwaogwugwu MC (2016) Study on the Properties of Coconut Shell Powder Reinforced High-Density Polyethylene Composite. Futojnls 43-55

39. Akaluzia RO, Edoziuno FO, Adediran AA, et al (2021) Evaluation of the effect of reinforcement particle sizes on the impact and hardness properties of hardwood charcoal particulate-polyester resin composites. Materials Today: Proceedings 38:570-577. https://doi.org/10.1016/j.matpr.2020.02.980

40. Zaaba NF, Ismail H (2019) A Review on Peanut Shell Powder Reinforced Polymer Composites. Polymer-Plastics Technology and Materials 58:349-365. https://doi.org/10.1080/03602559.2018.1471720

41. Surya Rajan B, Balaji MAS, Mohamed Aslam Noorani AB, et al (2019) Tribological performance evaluation of newly synthesized silane treated shell powders in friction composites. Materials Research Express 6:. https://doi.org/10.1088/2053-1591/ab08e0

42. Asmare Fentahun M, Ahsen Savaş M (2018) Materials Used in Automotive Manufacture and Material Selection Using Ashby Charts. International Journal of Materials Engineering 8:40-54. https://doi.org/10.5923/j.jme.20180803.02 


\section{Acknowledgments}

The authors would like to thank Mr. A.M. MoosaGani, Junior Assistant and Mr. John and Mrs. Veeralakshmi S, Lab technicians, at B. S. Abdur Rahman Crescent Institute of Science and Technology, Chennai, India for their immense support.

\section{Declaration of competing interest}

The authors have no competing interests to declare that are relevant to the content of this article. 